Л. П. Блощук, Н. А. Шинкарева. Анализ педагогических условий и особенности формирования представлений о материнстве у девочек старшего дошкольного возраста

Научная статья

УДК 373.2

DOI: $10.18101 / 2307-3330-2021-4-33-37$

\title{
АНАЛИЗ ПЕДАГОГИЧЕСКИХ УСЛОВИЙ И ОСОБЕННОСТИ ФОРМИРОВАНИЯ ПРЕДСТАВЛЕНИЙ О МАТЕРИНСТВЕ У ДЕВОЧЕК СТАРШЕГО ДОШКОЛЬНОГО ВОЗРАСТА
}

\author{
() Блощук Людмила Павловна \\ студентка, \\ Иркутский государственный университет \\ Россия, 664003, г. Иркутск, ул. Карла Маркса, 1 \\ uenlsxzqi5lz@mail.ru \\ (C) Шинкарева Надежда Алексеевна \\ кандидат педагогический наук, доцент, \\ Иркутский государственный университет \\ Россия, 664003, г. Иркутск, ул. Карла Маркса, 1 \\ Iren433@mail.ru
}

\begin{abstract}
Аннотация. В статье рассматриваются особенности организационно-педагогических условий для формирования представлений о материнстве у девочек старшего дошкольного возраста. Изучены взгляды авторов на данную проблему, где авторы дают определение понятию «материнство» и планируемые результаты освоения представлений о роли матери в семье в парциальных программах по социально-коммуникативному развитию старшего дошкольника. Уделяется внимание углубленной, целенаправленной работе педагога по формированию социальных основ материнства и отцовства, представлений о роли матери и отца в семье, происходит с использованием парциальных программ по социально-коммуникативному развитию дошкольника («Мир мальчика, мир девочки» Н. Е. Татаринцевой, «Мальчики и девочки. Дифференцированный подход к воспитанию детей старшего дошкольного возраста» И. П. Шелухиной, «Дорогою добра» (Л. В. Коломийченко и других). В статье представлены методики констатирующего этапа организации опытно-экспериментальной работы с родителями и педагогами в рамках темы исследования. Ключевые слова: понятие «материнство», старший дошкольный возраст, социализация, институт родительства.
\end{abstract}

\section{Для цитирования}

Блощук Л. П., Шинкарева Н. А. Анализ педагогических условий и особенности формирования представлений о материнстве у девочек старшего дошкольного возраста // Вестник Бурятского государственного университета. Образование. Личность. Общество. 2021. № 4. С. 33-37.

Одной из важнейших задач Федерального государственного образовательного стандарта является задача в пункте 1.6: развитие детей в соответствии с их возрастными и индивидуальными особенностями и склонностями; целевые ориентиры: ребенок обладает установкой положительного отношения к другим людям и самому себе; обладает начальными знаниями о себе, проявляет интерес к сверстникам, подражает им [2]. 
Знания человека о себе, его самосознание так же включает представление о полоролевом поведении людей, а оно, в свою очередь, представления о родительстве и материнстве.

Феномен материнства исследовался разными авторами: исследования материнского поведения и взаимодействия матери с ребенком в детской психологии (Е. О. Смирнова, С. Ю. Мещерякова, Н. Н. Авдеева и др.), культурно-историческая природа материнства (Г. Г. Филиппова), изучение эмоционального благополучия ребенка и его связи с типом материнского отношения (В. И. Перегуда, И. Ю. Ильина).

В настоящее время единого определения понятия «материнство», отражающего его многоаспектность (в том числе и педагогическую), нет. Г. Г. Филиппова определяет материнство как психосоциальный феномен: как обеспечение условий для развития ребенка, как часть личностной сферы женщины [4]. Все исследования, рассматривают его с позиций реализации биологической функции женщины, как осуществление института родительства посредством обеспечения условий жизни ребенка, его взращивания и социализации, как социальную функцию женщины [3].

Для успешной социализации ребенка, образ материнства необходимо формировать с детства, т.к. в качестве структурных единиц образ материнства содержит в себе образ собственной матери, образ идеальной матери, а для девочек образ себя в роли матери в будущем. В противном случае, неправильное половое воспитание может приводить к отклоняющемуся поведению ребенка, а в будущем к неэффективным способам взаимодействия в супружестве, в связи с чем, в современном обществе растет количество разводов и матерей, воспитывающих детей в одиночку [1].

Какие представления о материнстве должны сформироваться у детей на разных этапах дошкольного детства? Единого ответа на этот вопрос не существует. Углубленная, целенаправленная работа педагога по формированию социальных основ материнства и отцовства, представлений о роли матери и отца в семье, происходит с использованием парциальных программ по социально-коммуникативному развитию дошкольника («Мир мальчика, мир девочки» Н. Е. Татаринцевой, «Мальчики и девочки. Дифференцированный подход к воспитанию детей старшего дошкольного возраста» И. П. Шелухиной, «Дорогою добра» (Л. В. Коломийченко и других).

Конечно, для того, чтобы у детей сложились адекватные и полные представления о материнстве, сформировалась способность продемонстрировать свои умения в сюжетно-ролевой игре, необходима целенаправленная систематическая работа педагогов и включенность в этот процесс родителей.

Целью нашего исследования было выявить организационно-педагогические условия работы по формированию представлений о материнстве у девочек старшего дошкольного возраста в организационно-педагогических условиях МБДОУ Детский сад г. Иркутска. В исследовании приняли участие 10 педагогов.

Исследование компетентности педагогов и родителей в области формирования представлений о материнстве у девочек старшего дошкольного возраста происходило с помощью следующих методик: анкетирование родителей и педагогов, 
Л. П. Блощук, Н. А. Шинкарева. Анализ педагогических условий и особенности формирования представлений о материнстве у девочек старшего дошкольного возраста

анализ календарно- тематического планирования педагога-воспитателя, экспертиза Центра сюжетно-ролевой игры детсада.

Анализ содержательной составляющей и принципов организации «Центра для сюжетно-ролевых игр» показал недостаточный уровень оснащенности (50\%).

Так, в старшей группе в «Центре сюжетно-ролевых игр» принцип активности соблюдается частично: в группе есть 5-6 кукол, коляска и набор посуды, наличие которых подталкивает детей к игре в «Дочки-матери». Принцип эмоциогенности среды, индивидуальной комфортности и эмоционального благополучия каждого ребенка и взрослого не соблюден. Детям неудобно играть вместе или поодиночке, нет специального места для хранения кукол. Принцип учета половых и возрастных различий детей соблюдается частично. В группе все куклы - женского пола.

Проанализировав соответствие Примерному перечню, мы обнаружили, что куклы среднего размера только женского пола и не имеют сменных комплектов одежды и постельного белья. Отсутствуют фигурки 5-7 см, изображающие членов семьи и сказочных персонажей. Отсутствуют мебель для кукол, медицинские принадлежности и тематические строительные наборы, которые можно было бы объединить с куклами. Среди игрушек нет телефона, вертолета и самолета, кукольного дома, мебели для игры в «Школу», постельного белья для кукол.

По итогу диагностических методик для педагогов мы обнаружили следующие данные. Компетентность педагогов по изучаемому вопросу состояла из когнитивного, деятельностного и рефлексивного компонента.

Педагогов с высоким уровнем компетентности по вопросу формирования представлений о материнстве не обнаружено $(0 \%)$.

Педагоги со средним уровнем компетентности составляют 95\% от общего числа. Педагоги Надежда Б., Любовь Н. отмечают, что представления о материнстве заключается во взращивании и социализации ребенка. София Т. не знает, хочет ли она посетить мероприятия по повышению собственной компетентности в ДОУ. Марина К. не использует парциальных программ по формированию представлений о материнстве в работе с дошкольниками. Они не планируют свою работу по этому направлению, кроме как на День матери и 8 марта, и не берут эту тему для плана по самообразованию.

По результатам анкетирования мы обнаружили, что 5\% педагогов имеют низкий уровень компетентности по изучаемому вопросу. Педагог Анастасия П. не считает, что детям старшего дошкольного возраста следует рассказать о вынашивании и рождении детей матерями и о том, чем мать занимается на своей работе. Евгения Б. считает, что мальчикам не обязательно знать о материнстве. Воспитатель Надежда Л. считает, что представления о материнстве следует развивать только посредством чтения художественной литературы, а Татьяна Т. - занятий или бесед. Ева П. считает, что РППС группы следует пополнять раз в квартал.

Нами были собраны ответы родителей на анкету по вопросу формирования представлений о материнстве у детей старшего дошкольного возраста, которая состояла из когнитивного, деятельностного и мотивационного блоков. Родителей с достаточным уровнем представлений по изучаемому вопросу обнаружено не было $(0 \%)$, родители с частичным уровнем составили $90 \%$ от общего числа. Они считают, что они сами в первую очередь, должны рассказать ребенку о материнской 
роли и материнских функциях женщины (Вера К., Елена В.). Эти родители считают необходимым использовать народную куклу в процессе формирования представлений о материнстве у детей дошкольного возраста и готовы для собственной осведомленности посетить мероприятия по вопросу формирования представлений о материнстве через использование народной куклы (Елена В., Мария К.).

Родители с недостаточным уровнем представлений составляют $10 \%$. Девочки дошкольного возраста имеют дома куклы и берут роль матери на себя, а мальчикам-дошкольникам родители кукол не приобретают. Екатерина Б., показывает ребенку мультфильмы для формирования представлений о материнской роли женщины, а Никита Б. не считает нужным развивать представления о материнстве в этом возрасте. Родители не знают, что такое народная кукла, не показывали ее своему ребенку. Эти люди не готовы для собственной осведомленности посетить мероприятия по вопросу формирования представлений о материнстве (Евгения К., Наталья Ф. ответила: «Моя дочка не играет куклами, поэтому сомневаюсь, что ей будет это интересно»).

Таким образом, данные полученные в ходе диагностики подтвердили актуальность проблемы исследования и говорят о необходимости организации систематической работы по формированию представлений по данной теме у родителей и педагогов.

\section{Литература}

1. Мальцева Т. С. Формирование представлений о семейных ролях у детей старшего дошкольного возраста посредством сюжетно-ролевой игры. URL: https://vkr.pspu.ru/uploads/3691/Mal'tseva_vkr.PDF Загл. с экрана. Текст: электронный.

2. Об утверждении федерального государственного образовательного стандарта дошкольного образования: приказ Министерства образования и науки Российской Федерации от 17 октября 2013 г. № 1155 г. Москва. URL:http://rg.ru/2013/11/25/doshk-standartdok.html. Загл. с экрана. Текст: электронный.

3. Ушакова Е. Г. Представления о материнстве у женщин разных этносов: диссертация на соискание ученой степени кандидата психологических наук. Барнаул, 2008. 128 с. Текст: непосредственный.

4. Филиппова Г. Г. Психология материнства: учебное пособие. Москва: Институт психотерапии, 2002. 240 с. Текст: непосредственный.

Статья поступила в редакиию 02.10.2021; одобрена после рецензирования 13.10.2021; принята к публикачии 15.12.2021.

\section{ANALYSIS OF PEDAGOGICAL CONDITIONS AND FEATURES \\ OF MOTHERHOOD CONCEPT FORMATION OF SENIOR PRESCHOOL GIRLS}

Lyudmila P. Bloshchuk

student

Irkutsk State University

1 Karl Marx St., Irkutsk, 664003, Russia

uenlsxzqi5lz@mail.ru 
Л. П. Блощук, Н. А. Шинкарева. Анализ педагогических условий и особенности формирования представлений о материнстве у девочек старшего дошкольного возраста

\author{
Nadezhda A. Shinkareva \\ candidate of Pedagogical Sciences, Associate Professor \\ Irkutsk State University \\ 1 Karl Marx St., Irkutsk, 664003, Russia \\ Iren433@mail.ru
}

The article discusses the features of organizational and pedagogical conditions for motherhood concept formation of senior preschool girls. The authors gave their own view to this problem, gave a definition of the "motherhood" concept and the planned results of the development of ideas about the role of mother in family in partial programs on the sociocommunicative development of senior preschooler. The focus is on the in-depth, targeted work of a teacher to form the social foundations of motherhood and fatherhood, ideas about the role of mother and father in family, it occurs using partial programs on the social and communicative development of the preschoolers ("The World of Boy, the World of Girl" N.E. Tatarintseva, " Boys and girls. Differentiated approach to the upbringing of senior preschoolers" I.P. Shelukhina, "Advediture of Good "(L.V. Kolomiychenko and others).

The article presents the methods of the statement stage of the organization of experimental work with parents and teachers.

Keywords: the concept of «motherhood», senior preschool age, socialization, the institution of parenting.

The article was submitted 02.10.2021; approved after reviewing 13.10.2021; accepted for publication 15.12.2021. 